\title{
JENIS KOHERENSI KALIMAT DALAM RUBRIK CRIME STORY SURAT KABAR TRIBUN JAMBI EDISI MARET 2019
}

\author{
Firman Tara ${ }^{1}$, M. Arjun ${ }^{2}$ \\ Program Studi Pendidikan Bahasa dan Sastra Indonesia \\ Fakultas Keguruan dan Ilmu Pendidikan Universitas Batanghari \\ Jambi \\ firmantara14@gmail.com \\ arjunsuares703@gmail.com
}

\begin{abstract}
This study aims to describe the type of coherence in the column of crime story of Tribun Jambi March edition. This research uses qualitative descriptive method. Research Data is obtained by using documentation techniques. The data on this research is a sentence which contains of types of coherence, namely; cause and effect, addition, process, spatial, and indefinites. The source of the data is in the form of news text in the column of crime story of Tribun Jambi newspaper. Based on the results of the data anaylsis, it is found that there are 543 types of coherence in the crime story column of Tribun Jambi March edition 2019. There are 20 quotations of cause and effect which are characterized by three conjunctions, such as maka, jadi, and, sebaliknya. There are 293 types of addition coherence which are characterized with six conjunctions i.e. dan, selain itu, baik, maupun, serta, and di samping itu. There are 128 types of process coherence which are characterized with two conjunctions namely dengan and tanpa. There are 83 types of spatial coherence which are characterized by six conjunctions i.e., lalu, kemudian, setelah itu, pada saat itu, sebelumnya, and sementara itu. There are 19 quotations of indefinites coherence which are marked with four conjunctions i.e. bukan hanya, bahkan, selanjutnya, and lalu. Thus, it is found that the addition coherence as the dominant type which occurs in the column of crime story in Tribun Jambi newspaper March edition 2019. While the least coherence found in the data is indefinites coherence.
\end{abstract}

Keywords: Coherence Type, Newspaper, Tribun Jambi

\footnotetext{
${ }^{1}$ Dosen Program Studi Pendidikan Bahasa dan Sastra Indonesia, Fakultas Keguruan dan Ilmu Pendidikan, Universitas Batanghari, Jambi

${ }^{2}$ Mahasiswa Program Studi Pendidikan Bahasa dan Sastra Indonesia, Fakultas Keguruan dan Ilmu Pendidikan, Universitas Batanghari, Jambi
} 


\section{PENDAHULUAN}

Bahasa merupakan suatu alat komunikasi yang sangat penting bagi manusia. Sebagai makhluk sosial, manusia memerlukan bahasa sebagai alat komunikasi. Hasibuan dan Rofii (2019: 12) mengatakan Fungsi bahasa yang paling mendasar ialah sebagai alat komunikasi. Selain itu, bahasa juga berfungsi sebagai alat untuk bekerja sama di dalam kehidupan bermasyarakat (Chaer, 2011:2). Setiap anggota masyarakat dan komunitas tertentu selalu terlibat dalam komunikasi, baik bertindak sebagai komunikator (pembicara atau penulis) maupun sebagai komunikan (mitra-bicara, penyimak, atau pembaca) (Pernando dan A. Rahima, 2017:1)

Untuk berkomunikasi sebenarnya dapat juga digunakan cara lain, misalnya isyarat, lambang-lambang gambar atau kode-kode tertentu lainnya. Tetapi dengan bahasa komunikasi dapat berlangsung lebih baik dan lebih sempurna. Bahasa adalah alat komunikasi untuk bekerja sama dalam kehidupan manusia.

Dalam ilmu bahasa, terdapat banyak cabang ilmu seperti fonologi, sintaksis, morfologi, semantik dan wacana. Membicarakan bahasa tidak terlepas membicarakan kategori kebahasaan, yaitu wacana. Wacana adalah rentetan kalimat yang berkaitan sehingga terbentuklah makna yang serasi di antara kalimat-kalimat itu (Alwi dkk., 2010:41). Wacana dibentuk oleh paragraf-paragraf, sedangkan paragraf dibentuk oleh kalimat-kalimat. Paragraf haruslah merangkai kalimat satu dengan kalimat berikutnya dan harus berkaitan sehingga membentuk satu kesatuan yang utuh. Jadi, sebuah wacana yang utuh harus memiliki aspek yang lengkap, padu, dan menyatu. Penelitian tentang wacana penting dilakukan karena dengan wacana seseorang dapat memperoleh dan menyampaikan gagasan secara urut dan utuh. Selain itu, wacana merupakan satuan bahasa terlengkap.

Sebuah wacana yang utuh harus memiliki aspek yang lengkap, padu dan menyatu. Aspek itu, antara lain, kohesi, koherensi, topik wacana, aspek leksikal, aspek gramatikal, aspek fonologis dan aspek semantik. Wacana sangat dipengaruhi oleh aspek semantik (Rofii, 2017:20). Dapat dikatakan bahwa keutuhan wacana terjadi adanya keterkaitan antara teks dan konteksnya. Zaimar dan Ayu (2015:18) mengemukakan bahwa, koherensi adalah keterkaitan unsur-unsur dunia teks, misalnya susunan konsep atau gagasan, dan berkat hubungan-hubungan yang menggarisbawahi hal tersebut isi teks dapat dipahami dan relevan. Koherensi merupakan keterkaitan antara gagasan agar mudah dipahami. Koherensi menentukan keutuhan wacana dan koherensi berfungsi menghubungkan ujaran dalam makna saling melengkapi dan saling berkesinambungan. Menurut Pernando dan A Rahima (2017:2-3) koherensi tidak hanya berhubungan dengan bentuk tetapi juga berhubungan dengan makna. Wacana yang koheren akan membawa pengaruh kejelasan hubungan antara satuan bentuk yang satu dengan yang lain sehingga pesan yang ingin disampaikan dapat dipahami dengan jelas dan utuh.

Kalimat adalah satuan bahasa terkecil, dalam wujud lisan atau tulisan, yang mengungkapkan pikiran yang utuh (Alwi dkk., 2010:317). Kalimat adalah ungkapan pesan atau informasi, dan pikiran yang memiliki intonasi final (Rofii, 2015: 22). Kalimat merupakan satuan dasar wacana. Sebuah kalimat dikatakan koherensi apabila memiliki keterkaitan antara kalimat yang satu 
dengan yang lain dan apabila kalimat tidak berkaitan dengan kalimat yang lainnya maka kalimat itu tidak koherensi. Penelitian tentang koherensi kalimat penting untuk dilaksanakan karena koherensi berperan dalam menentukan efektif atau tidaknya sebuah kalimat. Selain itu, koherensi kalimat juga sangat berpengaruh terhadap terbentuknya suatu makna yang utuh.

Menurut Effendy (2014) "Surat kabar adalah lembaran tercetak yang memuat laporan yang terjadi di masyarakat dengan ciri-ciri terbit secara periodik, bersifat umum, isinya termasa dan aktual mengenai apa saja dan dimana saja di seluruh dunia untuk diketahui pembaca". Di Provinsi Jambi beberapa surat kabar seperti: Tribun Jambi, Jambi Independent, Jambi Ekspres dan lainlain.

Tribun Jambi memiliki beberapa keunggulan. Pertama, surat kabar ini termasuk dalam grup Kompas Gramedia dan cukup diminati oleh kalangan masyarakat. Kedua, surat kabar ini merupakan koran nomor 1 di Jambi berdasarkan Riset Nielsen Desember 2012. Ketiga, surat kabar Tribun Jambi sangat mudah didapatkan dan harganya terjangkau.

Dalam surat kabar terdapat berbagai jenis rubrik. Di dalam rubrik terdapat informasi baik berita, opini, dan iklan. Dalam surat kabar Tribun Jambi terdapat beberapa rubrik seperti, crime strory, tribun bisnis, tribun line, makalam square, tribun jual beli, dan lain lain. Rubrik crime story sangat menarik untuk dikaji karena dalam rubrik ini memuat informasi faktual. Rubrik crime story membahas masalah dunia kriminal atau perilaku kejahatan, baik itu berupa pencurian, pembunuhan, penipuan dan lain sebagainya.
Koherensi mempunyai peran untuk memelihara keterkaitan antarkalimat, sehingga wacana menjadi padu. Oleh sebab itu, diperlukan koherensi dalam menuliskan berita. Bagi penulis berita, koherensi sangat diperlukan agar kalimat yang digunakan koheren. Berikut ini merupakan contoh kalimat jenis koherensi hubungan cara.

Penulis memilih majalah kampus

LPM Patriotik, karena sebagai mahasiswa Program Studi Pendidikan Bahasa dan Sastra Indonesia Fakultas Keguruan dan Ilmu Pendidikan Universitas Batanghari penelitian ini sejalan dengan disiplin ilmu yang penulis telaah (dalam Skipsi Pernando, 2017:4).

Pada contoh di atas terdapat kata dengan. Kata dengan termasuk satu konjungsi yang terdapat dalam hubungan cara, berdasarkan teori Kridalaksana (dalam Junaiyah dan Zaenal, 2010:46), bahwa koherensi ditandai oleh salah satu bagian kalimat menyatakan cara dari apa yang dinyatakan oleh bagian lainnya.

Dari penjelasan di atas dapat disimpulkan bahwa, penelitian ini penting untuk dilaksanakan dengan pertimbangan sebagai berikut

1. Wacana sangat penting karena dengan wacana seseorang dapat memperoleh dan menyampaikan gagasan secara urut dan utuh.

2. Koherensi menentukan keutuhan wacana dan koherensi berfungsi menghubungkan ujaran dalam makna saling melengkapi dan saling berkesinambungan.

3. Koherensi kalimat sangat berpengaruh terhadap terbentuknya suatu makna yang utuh.

4. Banyak ditemukan kohenrensi kalimat dalam rubrik crime story yang membahsa membahas masalah 
dunia kriminal atau perilaku kejahatan.

\section{METODE PENELITIAN}

Sugiyono

$(2015: 3)$

mengemukakan "Jenis penelitian adalah cara ilmiah untuk mendapatkan data dengan tujuan dan kegunaan tertentu". Jenis penelitian ini adalah penelitian deskriptif. Penelitian deskriptif merupakan jenis penelitian kualitatif. Boglan dan Taylor (dalam Moleong, 2012:4) "Penelitian kualitatif adalah sebagai prosedur penelitian yang menghasilkan data deskriptif berupa kata-kata tertulis atau lisan dari orangorang dan perilaku yang dapat diamati”. Penelitian kualitatif berkaitan dengan data yang tidak berupa angka-angka, tetapi berupa kata-kata.

Berdasarkan pendapat para ahli di atas dapat disimpulkan bahwa metode yang digunakan dalam penelitian ini adalah penelitian deskriptif kualitatif. Hal yang dideskripsikan dalam penelitian ini adalah jenis koherensi kalimat dalam rubrik crime story surat kabar Tribun Jambi edisi Maret 2019”.

Data merupakan catatan atau keterangan untuk dianalisis. Subagyo (2006:87) mengemukakan "Data adalah semua keterangan seseorang yang dijadikan responden maupun yang berasal dari dokumen-dokumen baik dalam bentuk statistik atau dalam bentuk lainnya guna keperluan penelitian dimaksud". Dalam penelitian ini, data berupa kalimat atau kutipan-kutipan yang berkaitan tentang jenis koherensi yang terdapat dalam rubrik crime story surat kabar Tribun Jambi edisi Maret 2019.

Siswantoro

(2010:72)

mengemukakan "Sumber data terkait dengan subjek penelitian dari mana data diperoleh". Sumber data dalam penelitian ini adalah rubrik crime story surat kabar Tribun Jambi edisi Maret 2019.

Teknik pengumpulan data merupakan bagian penting dari proses penelitian. Sugiyono (2015:308) mengemukakan, "Teknik pengumpulan data merupakan langkah yang paling utama dalam penelitian, karena tujuan utama dari penelitian adalah mengumpulkan data". Teknik pengumpulan data yang digunakan dalam penelitian ini adalah

Ismawati

mengemukakan "Analisis data adalah proses mengorganisasikan dan mengurutkan data ke dalam pola, kategori, dan satuan uraian dasar sehingga dapat ditemukan tema dan dapat dirumuskan hipotesis kerja seperti yang disarankan oleh data. Teknik analisis data dalam penelitian ini, adalah teknik analisis isi yang dikemukakan oleh Miles dan Huberman (dalam Sugiyono, 2015:338-45), yang dilakukan dengan tiga langkah yaitu reduksi data (data reduction), penyajian data (data display), menarik kesimpulan (consclusion drawing).

\section{HASIL DAN PEMBAHASAN}

Pada bagian ini disajikan hasil penelitian berupa jenis koherensi kalimat yang terdapat dalam rubrik crime story surat kabar Tribun Jambi edisi Maret 2019. Berdasarkan hasil analisis data yang telah dilakukan, ditemukan jenis koherensi kalimat yang terdapat dalam rubric crime story surat kabar Tribun Jambi edisi Maret 2019 sebanyak 543 kutipan, yang terdiri atas 5 jenis koherensi, yaitu: hubungan sebab-akibat, hubungan penjumlahan, hubungan cara, hubungan beruntun, dan hubungan lebih.

\section{Hubungan Sebab-Akibat}


Menurut Kridalaksana (dalam Junaiyah dan Zaenal, 2010:46) hubungan sebab-akibat ditandai oleh bagian yang satu menyatakan sebab dan bagian yang lain menjadi akibat. Konjungsi yang digunakan pada hubungan ini, misalnya oleh sebab itu, jadi, akibatnya, oleh karena itu, maka, dengan demikian, jadi, Akibatnya. Hubungan sebab-akibat dalam rubrik crime story surat kabar Tribun Jambi edisi Maret 2019 ditemukan tiga konjungsi yaitu maka, jadi, dan akibatnya. Konjungsi maka mendominasi dari setiap kalimat yang terdapat dalam rubrik ini. Berikut contoh kutipan penggunaan konjungsi penanda hubungan sebab akibat.

\section{Kutipan 1}

Pada 24 Februari 2019 diketahui orang tersebut membawa narkotika yang saat itu berada di Provinsi Riau menuju Jambi. Maka pada 24 Februari 2019 pukul 21.00 WIB diketahui bahwa TO bergerak maju dengan satu unit mobil travel Kijang Inova.

Pada kutipan 1 terdapat konjungsi maka. Berdasarkan teori Kridalaksana (dalam Junaiyah dan Zaenal, 2010:46), konjungsi maka termasuk salah satu konjungsi yang terdapat dalam hubungan sebab-akibat. Hubungan sebab akibat, ditandai oleh bagian yang satu menyatakan sebab dan bagian yang lain menjadi akibat. Adapun bagian yang menyatakan sebab yaitu Pada 24 Februari 2019 diketahui orang tersebut membawa narkotika yang saat itu berada di Provinsi Riau menuju Jambi. Bagian yang menyatakan akibat yaitu Maka pada 24 Februari 2019 pukul 21.00 WIB diketahui bahwa TO bergerak maju dengan satu unit mobil travel Kijang Inova.

Kutipan 2
"Saya dak tau narkoba tu ado di bawah tv dekat kontrakan. Sayo dak pernah make dikontrakan pak. Saya biasa make di Pulau Pandan," katanya. Sebelumnya seorang wanita bernama $S$ terpaksa berurusan dengan hukum, setelah kedapatan memiliki dan menggunakan narkotika jenis sabu di rumahnya. Akibatnya ia menjalani persidangan di Pengadilan Negeri (PN) Jambi.

Pada kutipan 2 terdapat konjungsi akibatnya. Berdasarkan teori Kridalaksana (dalam Junaiyah dan Zaenal, 2010:46), konjungsi akibatnya termasuk salah satu konjungsi yang terdapat dalam hubungan sebab-akibat. Hubungan sebab akibat ditandai oleh bagian yang satu menyatakan sebab dan bagian yang lain menjadi akibat. Adapun bagian yang menyatakan sebab yaitu Sebelumnya seorang wanita bernama $S$ terpaksa berurusan dengan hukum, setelah kedapatan memiliki dan menggunakan narkotika jenis sabu di rumahnya. Bagian yang menyatakan akibat yaitu Akibatnya ia menjalani persidangan di Pengadilan Negeri (PN) Jambi.

Berdasarkan pembahasan tersebut, dapat disimpulkan bahwa jenis koherensi hubungan sebab-akibat yang terdapat dalam rubrik crime story surat kabar Tribun Jambi edisi Maret 2019 tidak terlalu mendominasi dan berada pada urutan keempat. Jenis koherensi hubungan sebab-akibat ditemukan tiga konjungsi yaitu maka, jadi, dan akibatnya sebanyak 20 kutipan.

\section{Hubungan Penjumlahan}

Kridalaksana (dalam Junaiyah dan Zaenal, 2010:47) mengemukakan hubungan penjumlahan menyatakan jumlah atau gabungan benda, kegiatan, keadaan, peristiwa, atau proses. 
Konjungsi yang digunakan dalam hubungan ini misalnya dan, serta, baik, maupun, di samping itu, lagi pula, lain dari itu, selain itu, dan kecuali itu. Hubungan penjumlahan dalam rubric crime story surat kabar Tribun Jambi edisi Maret 2019 ditemukan enam konjungsi yaitu dan, selain itu, baik, maupun, serta, dan di samping itu. Konjungsi dan mendominasi dari setiap kalimat yang terdapat dalam rubrik ini. Berikut contoh kutipan penggunaan konjungsi penanda hubungan penjumlahan.

Kutipan 3

Terdakwa Hasan dituntut 2 tahun penjara dan denda $R p 1$ miliar atas kepemilikan 56 ribu benih lobster pada sidang Pengadilan Negeri Jambi, Kamis (28/2).

Pada kutipan 3 terdapat konjungsi dan. Berdasarkan teori Kridalaksana (dalam Junaiyah dan Zaenal, 2010:47), konjungsi dan termasuk salah satu konjungsi yang terdapat dalam hubungan penjumlahan. Hubungan penjumlahan menyatakan jumlah atau gabungan benda, kegiatan, keadaan, peristiwa, atau proses. Pada kutipan 1, konjungsi dan digunakan untuk menghubungkan kata penjara dan denda.

Kutipan 2

Selain narkoba, BNNP juga mengamankan beberapa barang bukti lain di antaranya satu unit handphone Nokia E71 warna putih, tiket travel atas nama Ita, surat jalan CV. PO Jambi Indah Travel, kantong plastik warna biru serta tas perempuan berwarna coklat.

Pada kutipan 2 terdapat konjungsi

serta. Berdasarkan teori Kridalaksana (dalam Junaiyah dan Zaenal, 2010:47), konjungsi serta termasuk salah satu konjungsi yang terdapat dalam hubungan penjumlahan. Hubungan penjumlahan menyatakan jumlah atau gabungan benda, kegiatan, keadaan, peristiwa, atau proses. Pada kutipan 62, konjungsi serta digunakan untuk menghubungkan frasa kantong plastik warna biru serta tas perempuan berwarna coklat.

Kutipan 4

Dalam operasi ini petugas menurunkan anjing pelacak untuk mengendus apabila ada pengendara yang menyembunyikan narkoba di tempat yang tidak dapat dilihat oleh petugas, petugas juga melakukan tes urine di tempat untuk pengendara maupun penumpang yang dicurigai menggunakan narkoba.

Pada kutipan 4 terdapat konjungsi maupun. Berdasarkan teori Kridalaksana (dalam Junaiyah dan Zaenal, 2010:47), konjungsi maupun termasuk salah satu konjungsi yang terdapat dalam hubungan penjumlahan. Hubungan penjumlahan menyatakan jumlah atau gabungan benda, kegiatan, keadaan, peristiwa, atau proses. Pada kutipan 18, konjungsi maupun digunakan untuk menghubungkan kata pengendara maupun penumpang.

Berdasarkan pembahasan tersebut, dapat disimpulkan bahwa jenis koherensi hubungan penjumlahan yang terdapat dalam rubrik crime story surat kabar Tribun Jambi edisi Maret 2019 mendominasi dalam setiap kalimat. Jenis koherensi hubungan penjumlahan ditemukan enam konjungsi yaitu dan, selain itu, baik, maupun, serta, dan di samping itu sebanyak 243 kutipan.

\section{Hubungan Cara}

Kridalaksana (dalam Junaiyah dan Zaenal, 2010:48) mengemukakan "Hubungan cara ditandai oleh salah satu bagian kalimat menyatakan cara dari apa 
yang dinyatakan oleh bagian lainnya. Konjungsi yang digunakan dalam hubungan ini ialah dengan atau tanpa". Hubungan cara dalam rubrik crime story surat kabar Tribun Jambi edisi Maret 2019 ditemukan sebanyak 128 kutipan. Konjungsi dengan mendominasi setiap kalimat yang terdapat dalam rubric ini. Berikut dipaparkan contoh kutipan terkait konjungsi dengan.

\section{Kutipan 5}

Jaksa Penuntut Umum (JPU)

Kejari Jambi, Rendi dalam dakwaan yang dibacakan menyatakan telah bersalah dengan sengaja melakukan tindak pidana melawan hukum.

Pada kutipan 5 terdapat konjungsi dengan. Berdasarkan teori Kridalaksana (dalam Junaiyah dan Zaenal, 2010:48), konjungsi dengan termasuk salah satu konjungsi yang terdapat dalam hubungan cara. Hubungan cara ditandai oleh salah satu bagian kalimat menyatakan cara dari apa yang dinyatakan oleh bagian lainnya. Pada kutipan 1, konjungsi dengan digunakan untuk menghubungkan kata bersalah dengan sengaja.

Kutipan 6

Mereka melakukan atau turut serta melakukan kegiatan eksploitasi minyak bumi tanpa kontrak kerja sama dengan badan pelaksana.

Pada kutipan 6 terdapat konjungsi

tanpa. Berdasarkan teori Kridalaksana (dalam Junaiyah dan Zaenal, 2010:48), konjungsi tanpa termasuk salah satu konjungsi yang terdapat dalam hubungan cara. Hubungan cara ditandai oleh salah satu bagian kalimat menyatakan cara dari apa yang dinyatakan oleh bagian lainnya. Pada kutipan 37, konjungsi tanpa digunakan untuk menghubungkan frasa kegiatan eksploitasi minyak bumi tanpa kontrak kerja sama.
Berdasarkan hasil pembahasan tersebut, dapat disimpulkan bahwa jenis koherensi hubungan cara yang terdapat dalam rubrik Crime Story surat kabar Tribun Jambi edisi Maret 2019 berada pada urutan kedua setelah jenis koherensi hubungan penjumlahan yang mendominasi dari setiap kalimat. Jenis konjungsi hubungan cara ditemukan dua konjungsi yaitu dengan dan tanpa sebanyak 128 kutipan.

Kutipan 7

Pasangan ini menerima keputusan hakim dengan janji Ratna Dewi tidak akan mengulanginya, dan masih punya anak kecil serta merawat orang tua. Sebelumnya Ratna Dewi membacakan permohonannya pada hakim yang ditulis tangan pada selembar kertas folio.

Pada kutipan 7 terdapat konjungsi sebelumnya. Berdasarkan teori Kridalaksana (dalam Junaiyah dan Zaenal, 2010:49), konjungsi sebelumnya termasuk salah satu konjungsi yang terdapat dalam hubungan beruntun. Hubungan beruntun ditandai oleh apa yang dinyatakan pada bagian yang satu terjadi lebih dahulu daripada apa yang dinyatakan pada bagian lainnya. Bagian yang terjadi lebih dahulu yaitu: Pasangan ini menerima keputusan hakim dengan janji Ratna Dewi tidak akan mengulanginya, dan masih punya anak kecil serta merawat orang tua. Dihubungkan dengan: Sebelumnya Ratna Dewi membacakan permohonannya pada hakim yang ditulis tangan pada selembar kertas folio.

Kutipan 8

Pelaku yang berlari keluar menabrak pintu kaca hingga pecah. "Sudah nabrak pintu kaca, pintu pecah 
dia jatuh kemudian kita amankan" ujar security di RS tersebut.

Pada kutipan 8 terdapat konjungsi

kemudian. Berdasarkan teori

Kridalaksana (dalam Junaiyah dan Zaenal, 2010:49), konjungsi kemudian termasuk salah satu konjungsi yang terdapat dalam hubungan beruntun. Hubungan beruntun ditandai oleh apa yang dinyatakan pada bagian yang satu terjadi lebih dahulu daripada apa yang dinyatakan pada bagian lainnya. Bagian yang terjadi lebih dahulu yaitu: Sudah nabrak pintu kaca, pintu pecah dia jatuh. Dihubungkan dengan: kemudian kita amankan" ujar security di RS tersebut.

\section{Kutipan 9}

Aksi nekat bermula saat mereka sedang memancing di kolam kangkung, di dekat rumah kosong. Pada saat itu timbul niat terdakwa untuk masuk ke rumah tersebut, yang berada di Jalan Dr Setia Budi, Nomor 14 Rt 10 kelurahan Rajawali, Kecamatan Jambi Timur.

Pada kutipan 9 terdapat konjungsi

Pada saat itu. Berdasarkan teori Kridalaksana (dalam Junaiyah dan Zaenal, 2010:49), konjungsi Pada saat itu termasuk salah satu konjungsi yang terdapat dalam hubungan beruntun. Hubungan beruntun ditandai oleh apa yang dinyatakan pada bagian yang satu terjadi lebih dahulu daripada apa yang dinyatakan pada bagian lainnya. Bagian yang terjadi lebih dahulu yaitu Aksi nekat bermula saat mereka sedang memancing di kolam kangkung, di dekat rumah kosong. Dihubungkan dengan: Pada saat itu timbul niat terdakwa untuk masuk ke rumah tersebut, yang berada di Jalan Dr Setia Budi, Nomor 14 Rt 10 kelurahan Rajawali, Kecamatan Jambi Timur.

Berdasarkan hasil pembahasan di atas, dapat disimpulkan bahwa jenis koherensi hubungan beruntun yang terdapat dalam rubrik Crime Story surat kabar Tribun Jambi edisi Maret 2019 berada pada urutan ketiga setelah jenis koherensi hubungan cara. Jenis konjungsi hubungan beruntun ditemukan enam konjungsi yaitu lalu, kemudian, setelah itu, pada saat itu, sebelumnya, dan sementara itu sebanyak 83 kutipan.

\section{Hubungan Lebih}

Kridalaksana (dalam Junaiyah dan Zaenal, 2010:50) mengemukakan hubungan lebih memuat informasi yang menguatkan dan menandaskan informasi yang dinyatakan oleh bagian pertama. Konjungsi yang digunakan untuk itu, misalnya tidak hanya, tetapi juga, bukan hanya, melainkan juga, bahkan, malah, lebih-lebih lagi, apalagi, selanjutnya, tambahkan pula, di samping itu, lalu, berikutnya, demikian pula, begitu juga, di samping itu, dan lagi pula.

Hubungan lebih dalam rubrik crime story surat kabar Tribun Jambi edisi Maret 2019 ditemukan empat konjungsi yaitu bukan hanya, bahkan, selanjutnya, dan lalu. Konjungsi selanjutnya mendominasi dari setiap kalimat yang terdapat dalam rubric ini. Berikut contoh kutipan penggunaan konjungsi penanda hubungan lebih.

Kutipan 10

Pada 16 Februari dua tersangka, pada 21 Februari 2 orang tersangka TKP di Mendahara Ulu dengan BB 7 plastik kecil sabu berat 3,00 gram. Selanjutnya pada tanggal 28 Februari 2019 dua tersangka, lokasi Mendahara Ilir. BB 7 plastik kecil jenis sabu 1,16 gram.

Pada kutipan 10 terdapat konjungsi selanjutnya. Berdasarkan teori Kridalaksana (dalam Junaiyah dan Zaenal, 2010:50), konjungsi selanjutnya termasuk salah satu konjungsi yang 
terdapat dalam hubungan lebih. Hubungan lebih memuat informasi yang menguatkan dan menandaskan informasi yang dinyatakan oleh bagian pertama. Bagian pertama: Pada 16 Februari dua tersangka, pada 21 Februari 2 orang tersangka TKP di Mendahara Ulu dengan BB 7 plastik kecil sabu berat 3,00 gram. Bagian yang menguatkan: Selanjutnya pada tanggal 28 Februari 2019 dua tersangka, lokasi Mendahara Ilir. BB 7 plastik kecil jenis sabu 1,16 gram.

Kutipan 11

Selepas sidang ditutup, Solikin memeluk istrinya beberapa detik. Lalu menyalami rekannya yang hadir di ruang sidang.

Pada kutipan 11 terdapat konjungsi lalu. Berdasarkan teori Kridalaksana (dalam Junaiyah dan Zaenal, 2010:50), konjungsi lalu termasuk salah satu konjungsi yang terdapat dalam hubungan lebih. Hubungan lebih memuat informasi yang menguatkan dan menandaskan informasi yang dinyatakan oleh bagian pertama. Bagian pertama yaitu: Selepas sidang ditutup, Solikin memeluk istrinya beberapa detik. Bagian yang menguatka yaitu: Lalu menyalami rekannya yang hadir di ruang sidang.

Kutipan 12

Padahal kata Ibnu Haris, perairan timur provinsi Jambi cukup aktif dilalui kapal. Bahkan tak jarang Basarnas Jambi mendapat laporan untuk pencarian terkait kecelakaan laut. Bukan hanya bagi kapal, ia juga menghimbau agar para belayan di wilayah pantai timur Provinsi Jambi menggunakan Beacon.

Pada kutipan 12 terdapat konjungsi bahkan. berdasarkan teori
Kridalaksana (dalam Junaiyah dan Zaenal, 2010:50), konjungsi bahkan termasuk salah satu konjungsi yang terdapat dalam hubungan lebih. Hubungan lebih memuat informasi yang menguatkan dan menandaskan informasi yang dinyatakan oleh bagian pertama. Bagian pertama yaitu Padahal kata Ibnu Haris, perairan timur provinsi Jambi cukup aktif dilalui kapal. Bahkan tak jarang Basarnas Jambi mendapat laporan untuk pencarian terkait kecelakaan laut. Bagian yang menguatkan yaitu Bukan hanya bagi kapal, ia juga menghimbau agar para belayan di wilayah pantai timur Provinsi Jambi menggunakan Beacon.

Berdasarkan hasil pembahasan tersebut, dapat disimpulkan bahwa jenis koherensi hubungan lebih yang terdapat dalam rubrik crime story surat kabar Tribun Jambi edisi Maret 2019 berada pada urutan kelima dan paling sedikit ditemukan dalam setiap kalimat, dibandingkan jenis-jenis lainnya. Jenis koherensi hubungan lebih ditemukan empat konjungsi yaitu bukan hanya, bahkan, selanjutnya, dan lalu sebanyak 19 kutipan.

\section{SIMPULAN}

Berdasarkan hasil analisi data yang yang telah dilakukan dapat disimpulkan bahwa jenis koherensi kalimat dalam penelitian ini berupa hubungan sebab-akibat, hubungan penjumlahan, hubungan cara, hubungan beruntun, dan hubungan lebih dalam rubrik crime story surat kabar Tribun Jambi edisi Maret 2019 sebanyak 543 kutipan sebagai berikut.

1. Pada jenis koherensi kalimat hubungan sebab-akibat yang terdapat dalam rubrik crime story surat kabar Tribun Jambi edisi Maret 2019, ditemukan tiga konjungsi yaitu maka, 
jadi, dan akibatnya. Jumlah kutipan yang ditemukan sebanyak 20 kutipan.

2. Pada jenis koherensi kalimat hubungan penjumlahan yang terdapat dalam rubrik crime story surat kabar Tribun Jambi edisi Maret 2019, ditemukan enam konjungsi yaitu dan, Selain itu, baik, maupun, serta, dan di samping itu. Jumlah kutipan yang ditemukan sebanyak 293 kutipan.

3. Pada jenis koherensi kalimat hubungan cara yang terdapat dalam rubrik crime story surat kabar Tribun Jambi edisi Maret 2019, ditemukan dua konjungsi yaitu dengan dan tanpa. Jumlah kutipan yang ditemukan sebanyak 128 kutipan.

4. Pada jenis koherensi kalimat hubungan beruntun yang terdapat dalam rubrik crime story surat kabar Tribun Jambi edisi Maret 2019 ditemukan enam konjungsi yaitu lalu, kemudian, setelah itu, pada saat itu, sebelumnya, dan sementara itu. Jumlah kutipan yang ditemukan sebanyak 83 kutipan.

5. Pada jenis koherensi kalimat hubungan lebih yang terdapat dalam rubrik Crime Story surat kabar Tribun Jambi edisi Maret 2019, ditemukan empat konjungsi yaitu bukan hanya, bahkan, selanjutnya, dan lalu. Jumlah kutipan yang ditemukan sebanyak 19 kutipan.

\section{SARAN}

Berdasarkan simpulan terkait penggunaan koherensi dalam rubrik crime story surat kabar Tribun Jambi edisi Maret 2019, terdapat beberapa saran yang dapat disampaikan sebagai berikut.

1. Bagi penulis berita agar mampu menuliksan kalimat dengan koherensi yang tepat sehingga berita mudah dipahami.
2. Bagi para dosen Bahasa dan Sastra Indonesia agar mampu mengajarkan materi mengenai koherensi kalimat sehingga mahasiswa dapat memahaminya.

3. Bagi para pembaca khususnya mahasiswa Program Studi Pendidikan Bahasa dan Sastra Indonesia, hasil penelitian ini dapat digunakan untuk meningkatkan wawasan tentang bahasa.

4. Bagi peneliti lain, hasil penelitian ini adapat digunakan sebagai bahan referensi dalama melakukan penelitian.

\section{DAFTAR PUSTAKA}

Alwi, Hasan dkk. (2010). Tata Bahasa Baku Bahasa Indonesia. Jakarta: Rineka Cipta.

Chaer, Abdul. (2011). Tata Bahasa Praktis Bahasa Indonesia. Jakarta: Balai Pustaka.

Efendi (https://www.ejurnal.com/2014/02/pengertiansurat-kabar.html (diakses 12 Desember 2018).

Ismawati, Esti. (2012). Metode Penelitian Pendidikan Bahasa dan Sastra. Yogyakarta: Ombak.

Junaiyah, H.M, dan E. Zaenal Arifin. (2010). Keutuhan Wacana. Jakarta: Gramedia.

Moleong, Lexy J. (2012). Metode Penelitian Kualitatif Edisi Revisi. Bandung: PT. Remaja Rosdakarya.

Pernando, E. Dan A. Rahima. (2017). Analisis Kohesi Leksikal Dalam Majalah Patriotik LPM Universitas Batanghari Jambi Edisi XVI Juli-September Tahun 2016. Skripsi. Jambi: Pendidikan Bahasa dan Sastra Indonesia, 
Fakultas Keguruan dan Ilmu

Pendidikan, Universitas

Batanghari.

Rofii, Afif dan Hasibuan, Rizka Rani. (2019) Interferensi Bahasa Batak Mandailing dalam Tuturan Berbahasa Indonesia Pada Acara Parpunguan Masyarakat Mandailing Kota Jambi. Aksara. aksara.unbari.ac.id/index.php/aks ara/article/download/94/50.

Rofii, Afif. (2015). An Analysis Of Syntactical Ability Of Second Language Children Age 5-6 Years Old In Taman KanakKanak (TK) Para Bintang Kota Jambi. Jurnal Ilmiah Dikdaya Universitas Batanghari Jambi. dikdaya.unbari.ac.id/index.php/di kdaya/article/download/38/38

Rofii, Afif. (2017). Model of ContextualBased Semantics Learning Materials. Advances in Social Science, Education and Humanities Research (ASSEHR), volume 148. Sixth International Conference on Languages and Arts (ICLA 2017). https://download.atlantispress.com/article/25888900.pdf

Siswantoro. (2008). Metode Penelitian Sastra. Surakarta: Pusat Pelajar.

Subagyo, P. Joko. (2006). Metode Penelitian dalam Teori dan Praktek. Jakarta: Rineka Cipta.

Sugiyono. (2015). Metode Penelitian Kuantitatif Kualitatif dan $R \& D$. Bandung: Alfabeta.

Zaimar, Okke Kusuma Sumantri, dan Ayu Basoeki Harahap. (2015). Teori Wacana. Jakarta: Penaku. 